\title{
MINERAL TRIOXIDE AGGREGATE IN THE TREATMENT OF EXTERNAL INVASIVE RESORPTION: A CASE REPORT
}

\author{
Dr. Bhavesh Ahir ${ }^{1}$ Dr.Vaishali Parekh ${ }^{2}$ Dr. Anjali S. Vats ${ }^{3}$ Dr. Ankur Vats ${ }^{4}$ \\ ${ }^{1}$ Senior lecturer Dept of Conservative and Endodotics, ACPM Dental College,Dhule, Maharastra (India) \\ ${ }^{2}$ Professor and HOD. Dept of Conservative and Endodontics, K.M.Shah Dental College and Hospital,Vadodar (India) \\ ${ }^{3}$ Senior lecturer Dept of Conbservative and Endodontics, Bhojia Dental College \& Hospital, Distt. Solan, Himachal Pradesh (India) \\ ${ }^{4}$ Senior lecturer Dept of Conbservative and Endodontics, Bhojia Dental College \& Hospital, Distt. Solan, Himachal Pradesh (India) \\ Corresponding Author: \\ ${ }^{1}$ Mobile: 91909276833512 Email: drbhaveshendo@yahoo.com
}

\begin{abstract}
Received :

$14^{\text {th }}$ Sept, 2013

Accepted:

$2^{\text {nd }}$ Dec, 2013

Available online:

$28^{\text {th }}$ Dec, 2013

External invasive root resorption may occur as a consequence of trauma, orthodontic treatment, intracoronal bleaching and surgical procedures and may lead to the progressive and destructive loss of tooth structure. Depending on the extent of the resorptive process, different treatment regimens have been proposed. A 20-yearold female patient presented with tooth showing signs and symptoms of pain in 21 with extensive invasive resorption in middle third of root canal. After root canal treatment, The resorption area was chemomechanically debrided using ultrasonic tips and irrigant solution. MTA was used to fill the resorptive defect and the coronal access was temporarily sealed. Radiographs at 3 and 12 months showed adequate repair of the resorption and endodontic success. Clinically, the tooth was asymptomatic and found to be functioning well.
\end{abstract}

Keywords: Root resorption, Mineral Trioxide Aggregate, Guided Tissue regeneration.

\section{INTRODUCTION}

External invasive resorption is a rare form of external root resorption. It can occur in teeth with necrotic pulps, infected root canals, previously filled root canals and in vital teeth.

Traumatic injuries, orthodontic tooth movement, orthognathic and dento-alveolar surgery, periodontal treatment and internal bleaching have been identified as potential predisposing factors. ${ }^{1,2,3}$ Tronstad and Trope hypothesized a dual cause: injury and stimulation by sulcular microorganisms in the adjacent marginal tissues. ${ }^{4}$ This type of resorption can be classified as inflammatory resorption. ${ }^{5}$ Heithersay has recently quoted cases in the literature, which showed that the root resorption process is not a result of inflammation. ${ }^{6}$ In these cases, the resorption lacuna may be invaded by microorganisms at a later stage.

Clinically, external invasive resorption is often detected during routine radiographic examination. It could be associated with periodontal inflammation, a local 'pocket' may be detected; copious bleeding and spongy feeling are commonly observed at the site of the resorptive defect. ${ }^{6}$

Different approaches have been suggested for the treatment of external invasive resorption. To provide a clinical guide for debridement and filling of the resorption, Frank \& Torabinejad identified three different classes of resorption defect based on the location of the portal of entry in the cementum: supraosseus, crestal and intraosseus. ${ }^{7}$

Heithersay has suggested four different classes of invasive cervical resorption based on the extension and depth of the resorption within the radicular and coronal dentine. class 1 represents the shallowest penetration into the dentine with resorption generally located at the cervical level, whilst class 4 represents the most invasive resorptive process. ${ }^{8}$ Heithersay further emphasized the importance of using trichloroacetic acid to obtain complete curettage of the defect. ${ }^{3}$

After the chemo-mechanical debridement of the defect- glass-ionomer, light-cured resin composite, amalgam and mineral trioxide aggregate (MTA) 
combined with guided tissue regeneration have been recommended to restore the resorption and often associated bony defect. ${ }^{6}$

Mineral trioxide aggregate is a biocompatible cement $^{9}$ which has good sealing ability, and is moisture tolerant. When MTA was used to seal perforations in the furcal area, it induced repair of the periodontium, and new cementum formation over the material. $^{9}$

This case report describes the treatment of a maxillary central incisor with an invasive external resorption and an associated periodontal lesion.

\section{CASE REPORT}

A 20 year old female patient reported to the Department of Conservative and Endodontics with the chief complaint of pain in upper front teeth since 10 to 12 days. The pain was continuous and aggravated on having cold and hot food. Patient had a history of trauma and RCT in relation to 11,12 . Medical history was non contributory and no extra oral findings were present. Radiographic examination showed incomplete obturation and widening of PDL space in both the teeth (Figure 1). Based on the findings, it was decided to retreat the teeth. Guttapercha was completely removed from the root canals and confirmed with the IOPA. Radiographic examination showed the presence of radiolucent lesion on middle third of the root of 21 (Figure 2). Clinically, there was bleeding from root canal in relation to 21.On Examination with endodontic microscope, mid root resoption was observed on palatal side of root in relation to 21(Figure 3). Based on these findings, 'External Extensive root resorption' was diagnosed with 21 . It was planned to carry out routine root canal treatment followed by surgical repair of the defect on palatal side of root. Root canal treatment was performed in relation to 11 , 21 and obturation was done with lateral condensation technique. Blood investigation report was normal and consent was obtained from the patient. After administration of the local anesthesia, palatal flap was reflected till below the defect (Figures 3,4). After exposing the defect with the slow speed round bur it was slightly widened using an ultrasonic tip, and resorptive area was cleaned by rinsing with $5 \%$ of $\mathrm{NaOCl}$ and $17 \%$ EDTA. WMTA was properly condensed into the defect and non absorbable suture was placed for 7 Days (Fig 6). After 15 days the teeth were rehabilitated with fixed prosthetic crowns. Clinical and radiographic examination was performed at 3, 6 and 12 months. Radiographic examination after 12 months showed good adaption of MTA. Patient was asymptomatic.

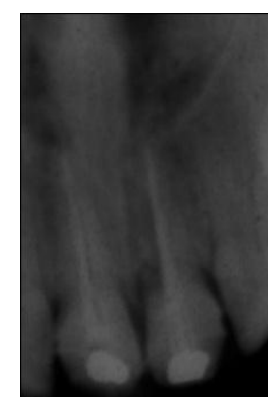

Figure 1: Incomplete root canal obturation and widening of PDL space

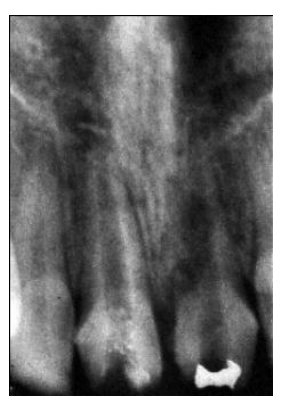

Figure 2: Presence of Figure radiolucency in middle exa third of root canal.

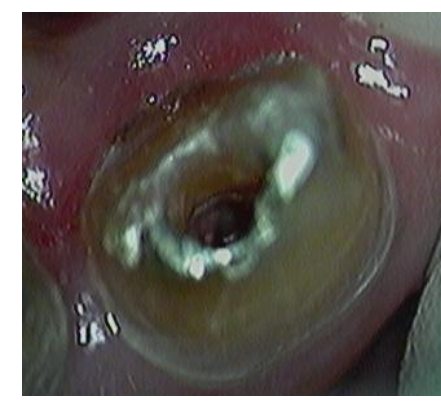

3: On microscopic examination presence of bleeding from palatal side of root

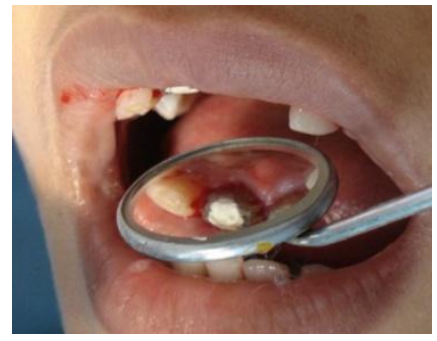

Figure 5: Palatal flap was reflected and MTA was placed in defect

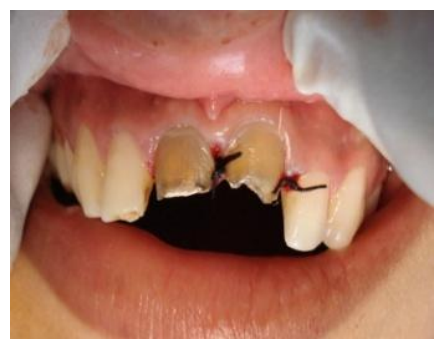

Figure 6: Suture has been placed for 7 days

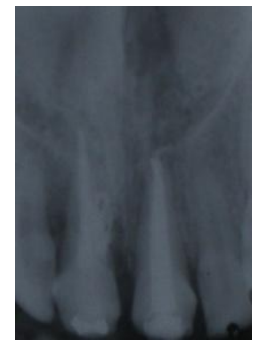

Figure 7: Post operative radiograph

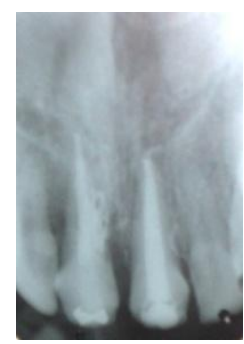

Figure 8: After 3 months radiograph 


\section{DISCUSSION}

The basic aim of treating external invasive resorption is the complete removal of resorptive tissue and restoration of the defect area because the pulp survives until late in the resorptive process. ${ }^{7}$

During the debridement of the resorptive lacuna, the use of chemical escharotic agents, such as trichloroacetic acid, improves the possibility of completely eliminating resorbing cells, which penetrate into the deeper parts of the defect and enhance the visualization of the defect. ${ }^{6}$ In the case presented, the resorptive area was debrided with ultrasonic tips, and alternating solutions of 5\% $\mathrm{NaOCl}$ and $17 \%$ EDTA. Finally, the area was rinsed with sterile water to enhance the adaptation of MTA. Mineral trioxide aggregate was chosen as the filling material for its biocompatibility ${ }^{9}$ and for its sealing ability. ${ }^{10}$ In previous studies, MTA was successfully used to repair communication between the pulp canal space and the periodontal tissue that occurs in cases of root perforation in $\operatorname{dogs}{ }^{11}$ and humans ${ }^{12}$, as well as in teeth with necrotic pulps and open apices ${ }^{1}$. Consistent with this case report, White \& Bryant ${ }^{14}$ reported an increase in radiodense crestal bone, when MTA was used in combination with guided tissue regeneration to fill an external root resorption associated with a bony defect. Heithersay affirmed that the prognosis of the treatment of invasive cervical resorption depends on the lesion class. In class 3 resorption, as in this case, he reported a $78 \%$ success.

This case is also interesting from an aetiological standpoint. The patient presented with only one of the recognized predisposing factors/causes, traumatic injury. He had neither received orthodontic treatment nor undergone any oral surgical procedure.

Although this case report presents a favourable outcome, further studies are encouraged to support the use of MTA to fill external invasive resorptions.

\section{REFERENCES}

1. Harrington GH, Natkin E External resorption associated with bleaching of pulpless teeth. Journal of Endodontics 1979;5:344-8.

2. Frank AL, Torabinejad $M$ Diagnosis and treatment of extracanal invasive resorption. Journal of Endodontics 1998;7:500-4.

3. Heithersay GS Invasive cervical resorption: an analysis of potential predisposing factors.Quintessence International 1999;30:83-95.

4. Gold SI, Hasselgren G Peripheral inflammatory root resorption. A review of literature with case reports. Journal of Clinical Periodontology 1992;19:523-534.

5. Bergmans L, Van Cleynenbreugel J, Verbeken E, Wevers M, Van Meerbeek B, lambrechts P Cervical external root resorption in vital teeth. X-ray microfocus-tomographical and histopathological case study. Journal of Clinical Periodontology 2002;29:560-85

6. Heithersay SG Invasive cervical resorption. Endodontic Topics 7:73-92.

7. Holland R, Filho JA, de Souza V, Nery MJ, Bernabe PF, Junior ED (2001) Mineral trioxide aggregate repair of lateral root perforations. Journal of Endodontics 2004;27:281-4.

8. Frank AL, Torabinejad M Diagnosis and treatment of extracanal invasive resorption. Journal of Endodontics 1998;7:500-4.

9. Heithersay GS Clinical, radiologic, and histopathologic feature of invasive cervical resorption. Quintessence International 1999;30:7-32.

10. Camilleri J, Montesin FE, Papaioannou S, McDonald F, Pitt Ford TR Biocompatibility of two commercial forms of mineral trioxide aggregate. International Endodontic Journal 2004;37:699-704.

11. Matt GD, Thorpe JR, Strother JM, McClanahan SB. Comparative study of white and grey mineral trioxide aggregate (MTA) simulating a one- or two-step apical barrier technique. Journal of Endodontics 2004;30:876-9.

12. Pitt Ford TR, Torabinejad M, McKendry DJ, Hong CU, Kariyawasam SP Use of mineral trioxide aggregate for repair of furcal perforations. Oral Surgery, Oral Medicine, Oral Pathology, Oral Radiology, and Endodontics 1995;79:756-63.

13. Main C, Mirzayan N, Shabahang S, Torabinejad M Repair of root perforations using mineral trioxide aggregate: a longterm study. Journal of Endodontics 2004;30:80-3.

14. Torabinejad M, Chivian M Clinical applications of mineral trioxide aggregate. Journal of Endodontics 2004;25:197205.

15. White $\mathrm{C}$, Bryant $\mathrm{N}$ Combined therapy of mineral trioxide aggregate and guided tissue regeneration in the treatment of external root resorption and associated osseous defect. Journal of Periodontology 2002;73:1517-21.

Source of Support: Nil, Confilict of Interst: None Declared 